\title{
Acrylonitrile Potentiates Noise-Induced Hearing Loss in Rat
}

\author{
Laurence D. Fechter, ${ }^{1}$ Caroline Gearhart, ${ }^{1}$ and Najeeb A. Shirwany ${ }^{2}$ \\ ${ }^{1}$ Research Service Jerry Pettis Memorial Veterans Medical Center, Loma Linda, CA 92357, USA \\ ${ }^{2}$ The Toxicology Program, Department of Pharmaceutical Sciences, University of Oklahoma Health Sciences Center, \\ Oklahoma City, OK 73190, USA
}

Received: 21 July 2003; Accepted: 14 October 2003; Online publication: 15 December 2003

\section{ABSTRACT}

Acrylonitrile, one of the 50 most commonly produced industrial chemicals, has recently been identified as a promoter of noise-induced hearing loss (NIHL). This agent has the potential to produce oxidative stress through multiple pathways. We hypothesize that acrylonitrile potentiates NIHL as a consequence of oxidative stress. The objectives of this study were to characterize acrylonitrile exposure conditions that promote permanent NIHL in rats and determine the ability of this nitrile to produce auditory dysfunction by itself. Additionally, we sought to determine whether a spin-trap agent that can form adducts with ROS would protect against the effects of acrylonitrile. Acrylonitrile administration produced significant elevation in NIHL detected as a loss in compound action potential sensitivity. The effect was particularly robust for high-frequency tones and particularly when acrylonitrile and noise were given on repeated occasions. Acrylonitrile by itself did not disrupt threshold sensitivity. Administration of the spin-trap agent phenyl- $\mathrm{N}$-tert-butylnitrone (PBN), given to rats prior to acrylonitrile and noise, did block the elevation of NIHL by acrylonitrile. However, PBN at the dose and time interval given was ineffective in protecting auditory function in subjects exposed to noise alone. The results suggest that oxidative stress may play a role in the promotion of NIHL by acrylonitrile.

Correspondence to: Laurence D. Fechter - Jerry Pettis Memorial Veterans Medical Center - Research Service (151) • 11201 Benton Street - Loma Linda, CA 92357. Telephone: (909) 825-7084 ext. 995; fax: (909) 796-4508; email: larry.fechter@med.va.gov
Keywords: ototoxicity, acrylonitrile, oxidative stress, potentiation of noise-induced hearing loss

\section{INTRODUCTION}

Three primary lines of evidence have implicated oxidative stress as an important mechanism that is involved in noise-induced hearing loss (NIHL). First, pharmacological studies have documented the ability of antioxidant drugs or prodrugs to block or reduce NIHL (e.g., Seidman et al. 1993; Yamasoba et al. 1999; Henderson et al. 1999). Second, genetic studies have demonstrated that laboratory animal models with reduced antioxidant buffering capacity are more vulnerable to NIHL than are wild-type subjects (e.g., Ohlemiller et al. 1999a, 2000). Finally, there are a limited number of reports with direct evidence of oxidative stress or of increased reactive oxygen species (ROS) in subjects who have been exposed to noise (e.g., Yamane et al. 1995; Ohlemiller et al. 1999b, 2000; Ohinata et al. 2000a,b).

There remain important questions concerning the extent of ROS generation as a function of noise severity and, in particular, whether moderate noise exposures can promote ROS formation. If moderate noise can promote ROS formation, then agents that disrupt ROS buffering and those that promote ROS formation might potentiate NIHL, even for noise exposures that produce little, if any, auditory impairment. There are a limited number of reports that are consistent with this hypothesis. For example, carbon monoxide promotes NIHL in rats and can promote ROS formation acutely in the cochlea 
(Fechter et al. 1997). However, the spin-trap agent, phenyl-N-tert-butylnitrone (PBN), can protect against such potentiation of NIHL (Rao and Fechter 2000). PBN is able to form adducts with ROS thereby reducing the likelihood of oxidative stress. The role of oxidative stress in cochlear injury has also been underscored as a consequence of aminoglycoside antibiotic (Garetz et al. 1994; Hester et al. 1998; Lautermann et al. 1997) and cisplatin (Rybak et al. 1995, 1999; Campbell et al. 1996, 1999; Kopke et al. 1997; Dehne et al. 2001). Both of these agents are widely recognized as promoting NIHL (e.g., Bone and Ryan 1978; Brown et al. 1980; Bhattacharyya and Dayal 1991; Gratton et al. 1990). In addition, Sha et al. (2001) suggested that the vulnerability of outer hair cells in the base of the cochlea to ototoxicants relative to the apex might reflect intrinsic glutathione (GSH) levels. They showed that GSH levels were higher in apical than in basal outer hair cells.

The objective of the current study was to determine whether a specific, widely used, commercial chemical, acrylonitrile (ACN), that is capable of disrupting intrinsic ROS buffering via well-studied pathways, would potentiate NIHL. Acrylonitrile is one of the 50 most commonly produced industrial chemicals in the world (Kirschner 1996). It is an "intermediate" compound used in the production of other materials including synthetic fabric such as nylon, polystyrene plastics, and nitrile rubber (IARC 1999). In the U.S. alone, it is produced in billions of pounds per year with estimated exposure to approximately 125,000 workers (Kirshner 1996) and the potential for significant contamination via accidental release into the environment.

The toxicity of ACN appears to be related specifically to its metabolism. The predominant metabolic pathway entails direct conjugation with glutathione (GSH) leading to depletion of this important antioxidant (e.g., Benz et al. 1997). Acrylonitrile is also metabolized by the mixed-function oxidase system (specifically by CYP2E1) yielding both a highly reactive epoxide and also cyanide (CN) (Langvardt 1980; van Bladeren et al. 1981). Thus, ACN might potentiate NIHL by at least two different routes that involve oxidative stress. By depleting GSH, acrylonitrile may render the ear more vulnerable to ROS generated by noise exposure. In addition, the production of $\mathrm{CN}$ would be expected to potentially inhibit the $\mathrm{Cu} / \mathrm{Zn}$ isozyme of superoxide dismutase which is found in cytosol (Weisiger and Fridovich 1973), thus impairing function of an antioxidant defense that has been associated with cochlear protection (Ohlemiller et al. 1999a; McFadden et al. 1999). In addition, CN can bind to cytochrome c oxidase (Way 1984) thereby disrupting electron transport (cf. Klassen 1996). In addition to these potential routes to ototoxicity, it is also possible that ACN could be ototoxic through some other, unidentified pathway. This study evaluates the effect of ACN on permanent NIH with the objective of delineating exposure conditions that yield potentiation of NIHL and assessing whether or not oxidative stress plays a role in such promotion. For the latter objective, the ability of a spin-trap agent, PBN, to protect against the potentiation of noise by ACN was assessed in male Long-Evans rats.

\section{METHODS}

\section{Subjects}

Ninety-two pigmented male Long-Evans rats (90-110 days old) obtained from Harlan (Indianapolis, IN) were used to characterize ACN exposure patterns that might promote NIHL and to determine whether a spin-trap agent could be protective against such effects. The subjects were housed in their home cages with free access to food and water. Background sound levels in the colony room were below $50 \mathrm{~dB}(\mathrm{~A})$. A 1/ 3 octave band analysis of this background noise level showed that sound levels in the frequency range used for threshold assessments $(2-40 \mathrm{kHz})$ in the rats were below $40 \mathrm{~dB}$. Temperature was maintained at $21 \pm 1^{\circ} \mathrm{C}$. Lights were on from 0630 to 1830 . Fortyeight rats were utilized at the University of Oklahoma Health Sciences Center in two experiments designed to characterize the effects of two different ACN dosing regimens on auditory function following noise exposure. The remaining 44 rats were tested at the Loma Linda Veterans Association for Research and Education (LLVARE) in a third experiment designed to replicate findings obtained in Oklahoma and to undertake protection studies using the antioxidant agent PBN. The experimental protocols were fully approved by the University of Oklahoma Health Services Center institutional animal care and use committee (IACUC) and by the Jerry Pettis Memorial Veterans Medical Center IACUC. All exposures and testing were performed during the daytime.

\section{Procedures}

Two experiments were conducted in succession. In the first experiment, the effects of a single ACN exposure on permanent NIHL was determined. In the second experiment, five daily ACN and noise exposures were utilized to evaluate the potentiation of permanent threshold shifts (PTS). For each study, six subjects were randomly assigned to each treatment group. Subjects received exposure to ACN alone, noise alone, the two agents in combination, and untreated controls. The groups were exposed to ACN alone $(50 \mathrm{mg} / \mathrm{kg} \mathrm{sc})$, octave band noise $(\mathrm{OBN})$ with 


\section{TABLE 1}

Treatment conditions for PBN experiment

Treatment

Acrylonitrile alone $(50 \mathrm{mg} / \mathrm{kg}$ sc $\times 5$ days) 5 Noise alone $\left(105 \mathrm{~dB}_{\text {lin }}\right.$ OBN for $4 \mathrm{~h} \times 5$ days)

Acrylonitrile + noise

PBN $(100 \mathrm{mg} / \mathrm{kg}$ IP $\times 2$ per day $\times 5$ days $)$

+ acrylonitrile + noise

$\mathrm{PBN}+$ noise

Untreated control rats

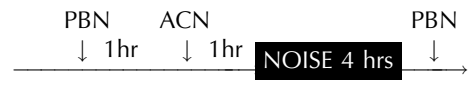

center frequency of $13.6 \mathrm{kHz}$ alone at an intensity of $105 \mathrm{~dB}$ for $4 \mathrm{~h}$, combined exposure to noise $+\mathrm{ACN}$, and a control condition that entailed placement of subjects in the exposure chamber with no further treatment. A $1 \mathrm{~h}$ rest interval was interposed between ACN injection and noise exposure in order to provide an adequate interval for GSH depletion and $\mathrm{CN}$ accumulation prior to noise exposure (Fechter et al. 2003). The effects of the five-day ACN dosing regimen on NIHL was subsequently replicated at LLVARE and extended using two additional groups that received treatment with the spin trap PBN prior to and following noise $+\mathrm{ACN}$ and $\mathrm{PBN}$ prior to and following noise alone. The treatment groups and the time relationships among the various treatments given are shown in Table 1.

Exposures were conducted in a reverberant $40 \mathrm{~L}$ glass cylinder. Air exchange rate within the chamber was $8.5 \mathrm{~L} / \mathrm{min}$ (providing approximately 12 changes per hour) with airflow being monitored by a Top Trak 821-1-PS flow gauge. The subjects were placed within small wire-cloth enclosures $(15 \times 13 \times 11 \mathrm{~cm})$ within the chamber. They were conscious and free to move within the enclosures.

Broadband noise was generated by a function generator (Stanford Research System, Model DS335, Menlo Park, CA) and bandpass filtered (Frequency Devices, 9002, Haverhill, MA) to provide an OBN with center frequency of $13.6 \mathrm{kHz}$. The rolloff for the filter system was $48 \mathrm{~dB}$ /octave. This signal was amplified by a Parasound HCA-1000A High Current Amplifier (Parasound Products Inc., San Francisco, CA) and fed to speakers (Vifa D25AG-05, Videbaek, Denmark) located approximately $5 \mathrm{~cm}$ above the subjects' wire-cloth enclosure. Sound intensity measured at the level of the rats' pinnae by a Quest Type 1 sound pressure meter (model 1700, Oconomowoc, WI) was $105 \mathrm{~dB}$. A $1 / 3$ octave band analysis of noise levels in the exposure chamber with $105 \mathrm{~dB}$ noise added and of ambient noise in quiet is provided in Figure 1.

\section{Auditory assessment}

Threshold assessment was performed four weeks following the end of experimental exposures by recording cochlear action potentials (CAP) from the round window for pure tones between 2 and $40 \mathrm{kHz}$ in approximately $1 / 2$ octave steps. Auditory thresholds were assessed in a double-walled audiometric booth. The subjects were anesthetized with xylazine $(13 \mathrm{mg} / \mathrm{kg} \mathrm{IM})$ and ketamine $(87 \mathrm{mg} / \mathrm{kg} \mathrm{IM})$, and normal body temperature was maintained using a DC heating unit built into the surgical table. The animals were tracheotomized. The auditory bulla was opened via a ventrolateral approach to allow the placement of a fine Teflon-coated silver wire electrode onto the round window. A silver chloride reference electrode was inserted into neck musculature. The temperature of the cochlea was maintained using a low-voltage high-intensity lamp. The CAP signals evoked by pure tones were amplified $1000 \times$ between 0.1 and $1.0 \mathrm{kHz}$ with a Grass AC preamplifier (Model P15, West Warwick, RI). The sound level necessary to generate a visually detectable CAP response on a digital oscilloscope (approximate response amplitude of $1 \mu \mathrm{V}$ ) was identified.

Pure tones for eliciting CAP were generated by a SR530 lock-in amplifier (Stanford Research Systems, Inc., Palo Alto, CA). A programmable attenuator controlled the tone intensity and the onset-offset ramps were set using a Wilsonics tone switch. The output of the attenuator was amplified by a highvoltage amplifier and then delivered to a 0.5 in. condenser microphone (ACO Pacific model No. 9475 , Belmont, CA) that served as the sound transducer. The transducer was placed into a plastic speculum that was aligned with the rat's external auditory canal. Auditory thresholds were determined for tones of 2, 4, 6, 8, 12, 16, 20, 24, 30, 35 and $40 \mathrm{kHz}$ using tone bursts of $10 \mathrm{~ms}$ duration with a rise/fall time of $1.0 \mathrm{~ms}$. The repetition rate of the tone bursts was 9.7 times/s. At the conclusion of testing, a $0.5 \mathrm{in}$. probe microphone (ACO Pacific model No. 4015) positioned near the eardrum was used to calibrate sound levels at all test frequencies for each subject.

\section{Statistical analyses}

The data were analyzed using NCSS software (Kaysville, UT). Repeated measures analyses of variance (ANOVAs) were used to evaluate the effects of experimental treatment (between subjects) on auditory thresholds at the various test frequencies (within subjects). Planned post hoc comparisons were 


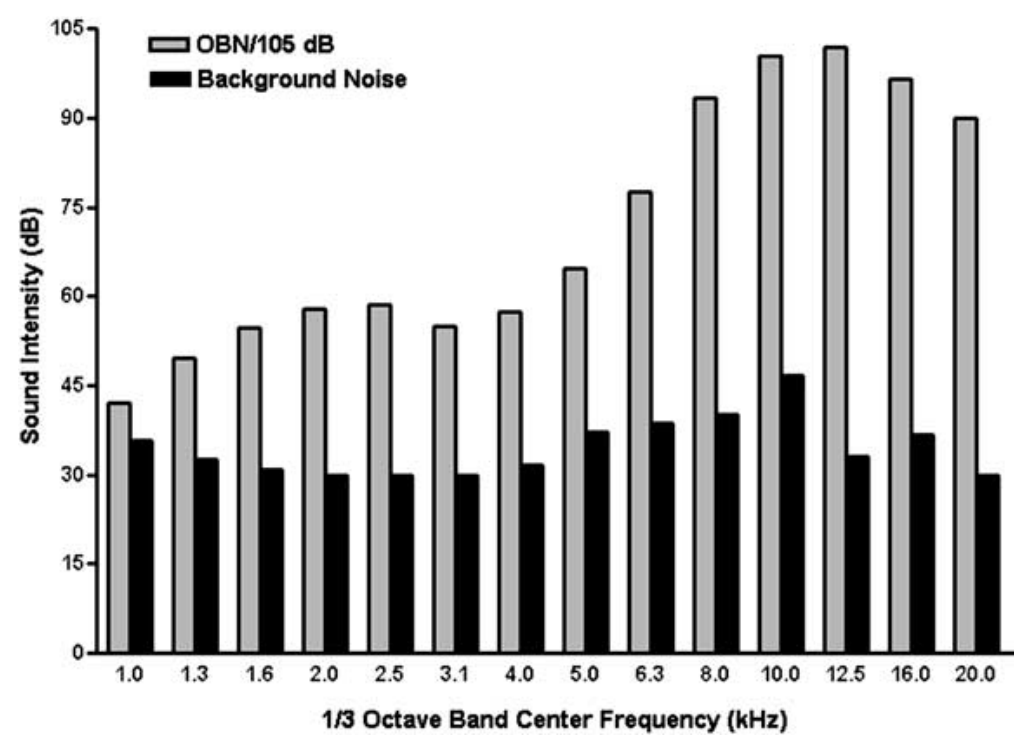

FIG. 1. Exposure chamber noise spectral analysis conducted using $1 / 3$ octave band filter system under conditions of noise exposure and quiet (ambient noise).

conducted between treatment groups using the Newman-Kuels test. Effects that exceeded a $p<0.05$ using two-tailed analyses were considered significant.

\section{RESULTS}

Figure 2 portrays the permanent effects of a single day's experimental treatment (ACN alone, noise alone, and ACN in combination with noise) on auditory thresholds in comparison with controls receiving no experimental treatment. Four weeks following treatment, a single ACN exposure $(50 \mathrm{mg} /$ $\mathrm{kg} \mathrm{sc})$ in combination with noise (105 dB OBN $4 \mathrm{~h}$ ) enhances NIHL for frequencies between 12 and 40 $\mathrm{kHz}$. In this frequency range, ACN elevated auditory thresholds on average $10 \mathrm{~dB}$ above the effect of noise alone. By contrast, ACN by itself did not alter auditory thresholds compared with control values. Finally, noise exposure alone did elevate auditory thresholds by an average of $10 \mathrm{~dB}$ above control values for frequencies between 12 and $40 \mathrm{kHz}$. There are no apparent differences among treatment groups for frequencies below the noise band utilized for exposures $(10-20 \mathrm{kHz})$.

A repeated measures ANOVA, in which experimental treatment served as a between-subject factor and frequency $(2-40 \mathrm{kHz})$ was a within-subject factor, showed statistically significant effects of treatment $\left(F_{3 / 13}=6.72, p=0.0056\right)$ and of frequency $\left(F_{10 / 130}=\right.$ $29.94, p<0.0001)$. The interaction term for treatment $\times$ frequency was not statistically significant $\left(F_{30 / 130}=\right.$ $1.46, p>0.05)$. Newman-Kuels multiple comparisons between groups identified significant differences between subjects exposed to ACN + noise and those receiving ACN only and no treatment (controls). The difference between the ACN + noise and the group

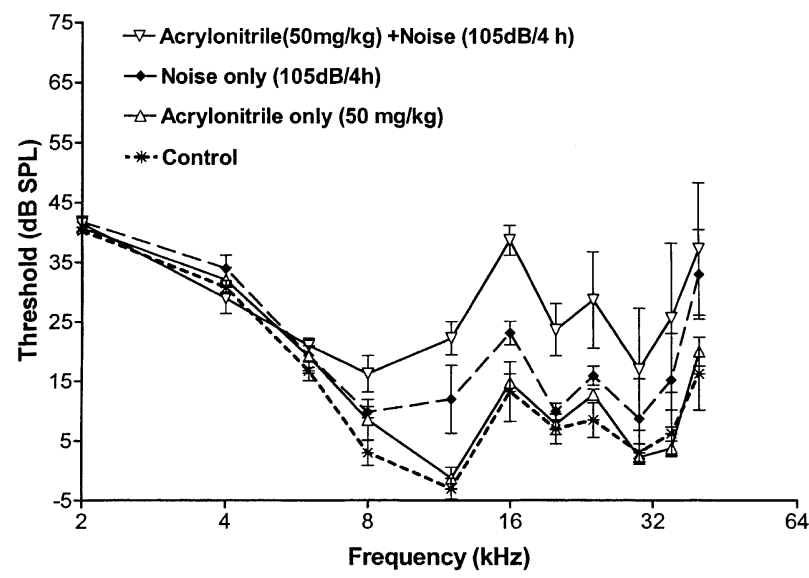

FIG. 2. Promotion of noise-induced hearing loss assessed four weeks following a single exposure to acrylonitrile $(50 \mathrm{mg} / \mathrm{kg} \mathrm{sc})$, noise ( $4 \mathrm{~h} 105 \mathrm{~dB}$ octave band noise), combined exposure to ACN followed $1 \mathrm{~h}$ later by noise exposure, and no experimental treatment. While noise alone elevated thresholds for high-frequency tones, the $\mathrm{ACN}$ treatment was able to significantly enhance this threshold shift. Acrylonitrile by itself did not produce a permanent threshold shift.

receiving noise alone failed to meet statistical significance. A separate repeated measures ANOVA limited to threshold data obtained only at or above the noise band was conducted. As in the more global analysis, treatment $\left(F_{3 / 13}=5.87, p<0.0005\right)$ and frequency $\left(F_{6 / 78}=11.76, p<0.0001\right)$ were significant while the interaction term was not significant $\left(F_{18 / 78}<1.0\right)$. In this case, Newman-Kuels multiple comparisons did indicate a significant difference between the group treated with both ACN + noise and the groups treated with noise alone, ACN alone, and untreated controls.

The disruption of auditory function by five daily $\mathrm{ACN}+$ noise treatments is shown in Figure 3. When assessed four weeks following the last experimental treatment, ACN elevated NIHL an average of 30-45 


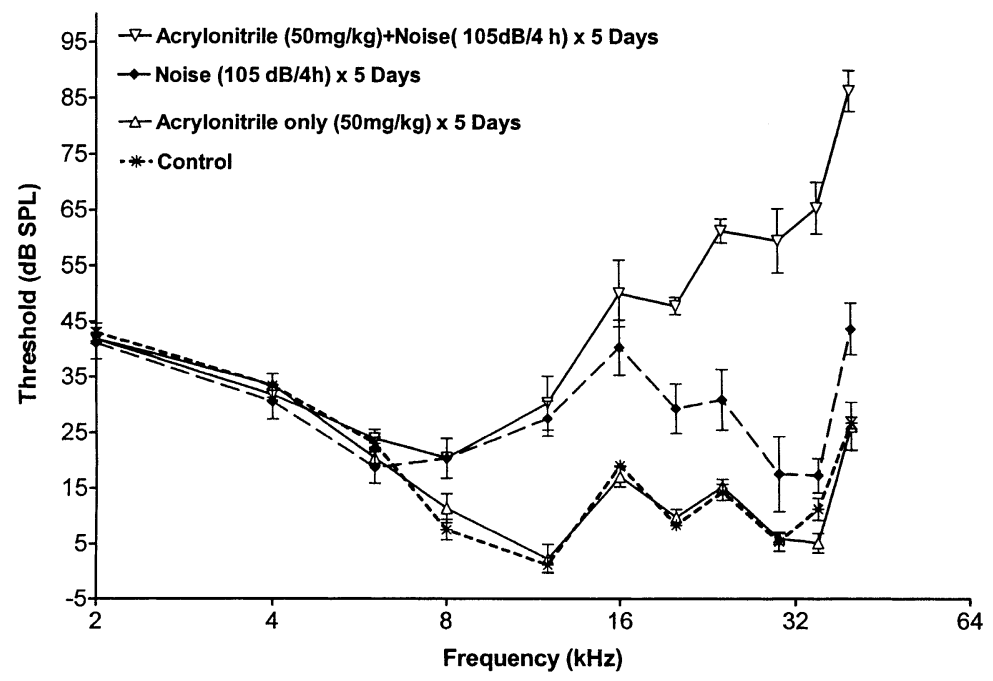

Fig. 3. Promotion of noise-induced hearing loss assessed four weeks following the last of five daily exposures to ACN (50 mg/kg sc), noise (4 h $105 \mathrm{~dB}$ octave band noise), combined exposure to $\mathrm{ACN}$ followed $1 \mathrm{~h}$ later by noise exposure, and no experimental treatment. While noise alone elevated thresholds for high-frequency tones, the ACN treatment was able to significantly enhance this threshold shift. Acrylonitrile by itself did not produce a permanent threshold shift.

$\mathrm{dB}$ at frequencies between 20 and $40 \mathrm{kHz}$ and by no more than $10 \mathrm{~dB}$ at frequencies below $16 \mathrm{kHz}$ relative to noise-treated subjects in the frequency range of $12-40 \mathrm{kHz}$. As in the single-treatment protocol (see Fig. 2), repeated ACN exposure had no effect upon auditory thresholds assessed four weeks later. Finally, repeated noise exposure elevated auditory thresholds an average of $17 \mathrm{~dB}$ above control rats in the frequency range of $12-40 \mathrm{kHz}$. A repeated measures ANOVA confirmed the differences in threshold sensitivity between groups $\left(F_{3 / 12}=64.06, p<0.0001\right)$. The main effect of frequency was also significant $\left(F_{10 / 120}=55.16, p<0.0001\right)$. In addition to significant main effects, the interaction of treatment $x$ frequency was also statistically significant $\left(F_{30 / 120}=\right.$ 20.01, $p<0.0001)$. Newman-Kuels multiple comparisons showed a significant difference between the group that received ACN + noise and all other treatment groups. Noise also elevated auditory thresholds significantly relative to the untreated controls, while ACN by itself did not elevate thresholds above control levels.

Figure 4 shows the effect of the spin-trap agent PBN on promotion of NIHL by ACN over five daily exposures. As in the previous experiment, ACN potentiated NIHL, elevating the auditory threshold an average of $14 \mathrm{~dB}$ over the frequency range 12-40 kHz. Similarly, noise exposure produced a clear impairment (averaging $24 \mathrm{~dB}$ ) in auditory threshold relative to control subjects. However, subjects treated with PBN prior to and again following ACN + noise treatment show approximately the same auditory impairment as do rats receiving noise by itself. That is, PBN blocked the potentiation of NIHL by ACN. However, it did not prevent an impairment of auditory function of the same order of magnitude as did noise only. Similarly, a comparison between groups receiving noise alone and PBN prior to and again following

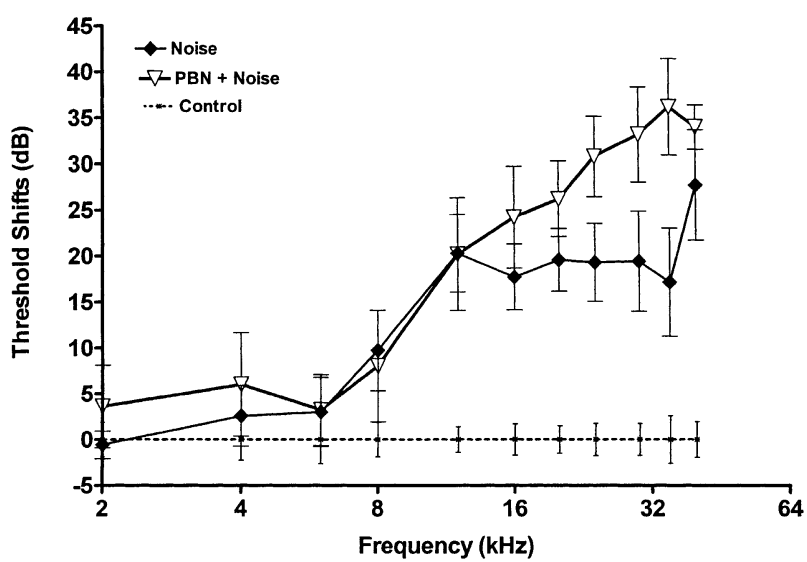

FIG. 4. Protective effects of PBN $(2 \times 100 \mathrm{mg} / \mathrm{kg}$ IP $)$ against the promotion of noise-induced hearing loss by ACN (50 mg/kg sc) + noise (105 dB OBN 4 h) given on five successive days. Thresholds were assessed four weeks later. PBN was administered 60 min prior to $\mathrm{ACN}$ and, again, immediately following termination of noise exposure.

noise did not disclose a noticeable difference in auditory function between these two groups (see Fig. 5).

A repeated measures ANOVA conducted on data presented in Figures 4 and 5 confirmed the differences in threshold sensitivity between groups $\left(F_{5 / 37}=\right.$ $12.28, p<0.0001)$. The main effect of frequency $(2-40 \mathrm{kHz})$ was also significant $\left(F_{10 / 370}=134.05, p<\right.$ $0.0001)$. In addition to significant main effects, the interaction of treatment $\times$ frequency was also statistically significant $\left(F_{50 / 370}=9.55, p<0.0001\right)$. The results of this study replicate the findings of experiment 2. Newman-Kuels comparisons demonstrated that combined treatment with ACN + noise produced significantly greater auditory impairment than did noise alone, and noise by itself did produce a permanent threshold shift (PTS) relative to control subjects. Acrylonitrile by itself did not produce a PTS. Newman-Kuels multiple-comparison tests showed a 
a relationship was the basis of predicting, correctly, that acrylonitrile would promote NIHL.

This study also shows that PBN does not protect auditory function against noise at the exposure levels used here, a finding that is inconsistent with reports of therapeutic effects obtained using several other antioxidant drugs. For example, Quirk et al. (1994) showed that a lipid peroxidase inhibitor (U7 4389F) could reduce auditory impairment produced by 90 $\mathrm{dB}$ noise exposure for $60 \mathrm{~h}$ in rats. Seidman et al. (1993) showed that allopurinol and SOD-PEG could reduce NIHL in rats exposed for $60 \mathrm{~h}$ to continuous broadband noise (90 dB). Kopke et al. (2002) demonstrated that acetyl-L-carnitine and D-methionine could both reduce NIHL and hair cell injury in chinchillas exposed to OBN for $6 \mathrm{~h}$ at $105 \mathrm{~dB}$. Yamasoba et al. (1999) showed that the iron chelator desferoxamine, alone or in combination with mannitol, could protect against NIHL produced in the guinea pig using OBN of $115 \mathrm{~dB}$ for $5 \mathrm{~h}$. Henderson et al. 1999) showed that R-PIA and glutathione monoethylester treatment reduced auditory impairment in chinchillas receiving $150 \mathrm{~dB}$ impulse noise. The lack of protection by PBN against NIHL may reflect several different factors including the $2 \mathrm{~h}$ time interval between PBN injection and onset of a $4 \mathrm{~h}$ noise exposure. Chen et al. (1990) showed that peak PBN levels in liver, kidney, and lung were attained 30 min after IP PBN administration and that tissue PBN concentrations were declining at $60 \mathrm{~min}$ post injection. While appreciable PBN remains in tissue at 120 min postinjection, these levels may not be inadequate to protect fully against noise treatment. TrudeauLame et al. (2003) recently reported that the $T_{1 / 2}$ for $\mathrm{PBN}$ in plasma following IV injection in rats is $2 \mathrm{~h}$. In light of this recent evidence, the administration of PBN in closer time proximity to noise exposure would be important in determining its efficacy with respect to noise treatment alone. Another explanation for this lack of efficacy is that the antioxidant action of PBN is associated with adduct formation with ROS. The strategy that has been most frequently employed by other investigators is to enhance intrinsic ROS buffers such as GSH levels and SOD levels in an effort to prevent oxidative stress due to noise. Perhaps this difference in mechanism of drug action might account for the difference in drug activity. Additionally, it should be appreciated that the ability of drugs to reduce NIHL will be related also to noise intensity and duration. These variables presumably relate to the degree to which the specific noise exposure does generate ROS. Generally, the studies identified as showing positive outcomes have used more severe noise exposure than that employed here. One exception to this is the paper by Kopke et al. (2002) in which chinchillas received $6 \mathrm{~h}$ of $\mathrm{OBN}$ at $105 \mathrm{~dB}$.
While this is comparable in absolute terms to our exposure ( $4 \mathrm{~h} \mathrm{OBN}$ at $105 \mathrm{~dB}$ ), the degree of auditory threshold shift appears to be substantially larger in the chinchilla than we observed in the rat.

The current failure to obtain protection against NIHL using an antioxidant drug is not unique. First, it might well be appreciated that published papers would be biased toward positive results in using antioxidants to protect against NIHL and that failures to detect protection by antioxidants against NIHL might go unreported. However, others have also reported mixed results. Hight et al. (2003) reported that glutathione monomethylester and R-PIA were effective in reducing auditory impairment and damage due to impulse noise in the chinchilla, but that these drugs were either ineffective or less effective in reducing NIHL resulting from continuous OBN of $105 \mathrm{~dB}$ for $4 \mathrm{~h}$. In terms of drug efficacy, it was previously noted that $\mathrm{PBN}$ protects against the potentiation of NIHL by a chemical contaminant but does not protect against NIHL itself (Rao and Fechter 2000). Thus, the current data with respect to PBN and NIHL provides somewhat of a conundrum. Direct comparisons between $\mathrm{PBN}$ and other antioxidant drugs in protecting both against ACN + noise and noise alone along with further studies using different noise exposures will be important in distinguishing among these different explanations.

\section{ACKNOWLEDGMENTS}

This research was supported in part by a research grant from NIDCD-NIH (DC05503). The authors are grateful to Dr. Y. Kotake of the Oklahoma Medical Research Foundation who synthesized the PBN.

\section{REFERENCES}

Benz FW, Nerland DE, Li J, Corbett D. Dose dependence of covalent binding of acrylonitrile to tissue protein and globin in rats. Fundam. Appl. Toxicol. 36:149-156, 1997.

Bhattacharyy TK, Dayal VS. Potentiation of cochlear hair cell loss by acoustic stimulus and gentamicin in the guinea pig. Anat. Rec. 230(1):136-145, 1991.

Bone RC, Ryan AF. Audiometric and histologic correlates of the interaction between kanamycin and subtraumatic levels of noise in the chinchilla. Otolaryngology. 86(3 Pt 1):RL400-404, 1978.

Brown JJ, Brummett RE, Fox KE, Bendrick TW. Combined effects of noise and kanamycin. Cochlear pathology and pharmacology. Arch. Otolaryngol. 106(12):744-750, 1980.

Campbell KCM, Rybak LP, MeEch RP, Hughes L. D-Methionine provides excellent protection from cisplatin ototoxicity in the rat. Hear. Res. 102:90-98, 1996.

Campbell KC, Meech RP, Rybak LP, Hughes LF. D-Methionine protects against cisplatin damage to the stria vascularis. Hear. Res. 138(1-2):13-28, 1999.

Campo P, Lataye R, Cossec B, Placidi V. Toluene-induced hearing loss: A mid-frequency location of the cochlear lesions. Neurotoxicol. Teratol. 19:129-140, 1997. 
Chen GD, Fechter LD. Potentiation of octave-band noise induced auditory impairment by carbon monoxide. Hear. Res. 132:149159, 1999.

Chen GD, McWilliams M, Fechter LD. Intermittent noise induced hearing loss and the influence of carbon monoxide. Hear. Res. 138:181-191, 1999.

Chen GM, Bray TM, Janzen EG, McCay PB. Excretion, metabolism and tissue distribution of a spin trapping agent, alpha-phenyl- $N$ tert-butyl-nitrone $(\mathrm{PBN})$ in rats. Free Radic. Res. Commun. 9:317-323, 1990.

Crofton KM, Zhao X. The ototoxicity of trichloroethylene: extrapolation and relevance of high-concentration, short-duration animal exposure data. Fundam. Appl. Toxicol. 38:101-106, 1997.

Crofton KM, LAssiter TL, REBERT CS. Solvent induced ototoxicity in rats: an atypical selective mid-frequency hearing deficit. Hear. Res. 80:25-30, 1994.

Dehne N, Lautermann J, Petrat F, Rauen U, de Groot H. Cisplatin ototoxicity: involvement of iron and enhanced formation of superoxide anion radicals. Toxicol. Appl. Pharmacol. 174(1):27-34, 2001.

FECHTER LD. A mechanistic basis for interactions between noise and chemical exposure. Arch. Com. Environ. St. 1:23-28, 1989.

Fechter LD, Young JS, Carlisle L. Potentiation of noise induced threshold shifts and hair cell loss by carbon monoxide. Hear. Res. 34:39-47, 1988.

Fechter LD, Liu Y, Pearce TA. Cochlear protection from carbon monoxide exposure by free radical blockers in the guinea pig. Toxicol. Appl. Pharmacol. 142:47-55, 1997.

Fechter LD, Liu Y, Herr DW, Crofton KM. Trichloroethylene ototoxicity: evidence for a cochlear origin. Toxicol. Sci. 28-35, 1998

Fechter LD, Johnson DL, Chen GD. Potentiation of noise induced hearing loss by low concentrations of hydrogen cyanide in rats. Toxicol. Sci. 66:131-138, 2002.

Fechter LD, Klis SFL, Shirwany NA, Moore TG, Rao DB. Acrylonitrile produces transient cochlear function loss and potentiates permanent noise-induced hearing loss. Toxicological Sciences 75:117-123, 2003.

Gabaizadeh R, Staecker H, Liu W, Kopke R, Malgrange B, Lefebvre TR, VAN DE WATER TR. Protection of both auditory hair cells and auditory neurons from cisplatin induced damage. Acta Otolaryngol. 117:232-238, 1997.

Garetz SL, Altschuler RA, Schacht J. Attenuation of gentamicin ototoxicity by glutathione in the guinea pig in vivo. Hear. Res. 77:81-87, 1994

Gratton MA, Salvi RJ, Kamen BA, Saunders SS. Interaction of cisplatin and noise on the peripheral auditory system. Hear. Res. 50(1-2):211-223, 1990.

Henderson D, McFadden SL, Liu CC, Hight N, Zheng XY. The role of antioxidants in protection from impulse noise. Ann. NY Acad. Sci. 884:368-380, 1999.

Hester TO, Jones RO, Clerici WJ. Protection against aminoglycoside otic drop-induced ototoxicity by a spin trap: I. Acute effects. Otolaryngol. Head Neck Surg. 119:581-587, 1998.

International Agency for Research on Cancer. Monographs on the evaluation of the carcinogenic risk of chemicals to humans. IARC Sci. Publ. 71(Pt 1):43-108, 1999.

Hoffman DW, Whitworth CA, Jones KL, Rybak LP. Nutritutional status, glutathione levels, and ototoxicity of loop diuretics and aminoglycoside antibiotics. Hear Res. 31:217-222, 1987.

Hoffman DW, Whitworth CA, Jones KL, Rybak LP. Potentiation of ototoxicity of glutathione depletion. Ann. Otol. Rhino. Laryngol. 97:36-41, 1988.

Johnson AC, Juntunen L, Nylen P, Borg E, Hoglund G. Effect of interaction between noise and toluene on auditory function in the rat. Acta Otolaryngol. 105:56-63, 1988.
KIRSCHNER EM. Production of top 50 chemicals increased substantially in 1994. Chem. Eng. News. 10-22, 1996.

KLassen CD. Cassarett \& Doull's Toxicology, 5th ed. McGraw Hill, New York, p 55-56, 1996.

Kopke RD, Liu W, Gabaizadeh R, Jacono A, Feghali J, Spray D, Garcia H, Steinman H, Malgrange B, Ruben RJ, Rybak L, Van de Water TR. Use of organotypic cultures of Corti's organ to study the protective effects of antioxidant molecules on cisplatin-induced damage of auditory hair cells. Am. J. Otol. 18:559-571, 1997.

Kopke RD, Coleman JK, Liu J, Campbell KC, Riffenburgh RH. Candidate's thesis: enhancing intrinsic cochlear stress defenses to reduce noise-induced hearing loss. Laryngology. 112(9): 1515-1532, 2002.

Langvardt PW, Putzig CL, Braun WH, Young JD. Identification of the major urinary metabolites of acrylonitrile in the rat. $\mathrm{J}$. Toxicol. Environ. Health. 6(2):273-282, 1980.

Lautermann J, Crann SA, McLaren J, Schacht J. Glutathione-dependent antioxidant systems in the mammalian inner ear: effects of aging, ototoxic drugs and noise. Hear. Res. 114:75-82, 1997.

McFadden SL, Ding D, Burkard RF, Jiang H, Reaume AG, Flood RJ, SALVI RJ. Cu/Zn SOD deficiency potentiates hearing loss and cochlear pathology in aged 129, CD-1 mice. J. Comp. Neurol. 413(1):101-112, 1999.

Morata TC, Dunn DE, Kretschmer LW, LeMasters GK, Keith RW. Effects of occupational exposure to organic solvents and noise on hearing. Scand. J. Work. Environ. Health 19:245-254, 1993.

Morata TC, Dunn DE, Sieber WK. Occupational exposure to noise and ototoxic organic solvents. Arch. Environ. Health 49:359$365,1994$.

Morata TC, Engel T, Durao A, Costa TR, Krieg EF, Dunn DE, Lozano MA. Hearing loss from combined exposures among petroleum refinery workers. Scand. Audiol. 26:141-149, 1997a.

Morata TC, Fiorini AC, Fischer FM, Colacioppo S, Wallingford EF, Krieg EF, Dunn De, Gozzoli l, Padrao ma, Cesar Cl. Toluene induced hearing loss among rotogravure printing workers. Scand. J. Work. Environ. Health 23(4):289-298, 1997b.

Ohinata Y, Miller JM, Altschuler RA, Schacht J. Intense noise induces formation of vasoactive lipid peroxidation products in the cochlea. Brain. Res. 878(1-2):163-173, 2000a.

Ohinata Y, Yamasoba T, Schacht J, Miller JM. Glutathione limits noise-induced hearing loss. Hearing. Res. 146(1-2):28-34, 2000b.

Ohlemiller K, McFadden S, Ding D, Flood D, Reaume A, Hoffman R, Scott R, Wright J, Putcha G, SAlvi R. Targeted deletion of the cytosolic $\mathrm{Cu} / \mathrm{Zn}$-superoxide dismutase Gene (Sod1) increases susceptibility to noise-induced hearing loss. Audiol. Neurootol. 4:237-246, 1999a.

Ohlemiller KK, Wright JS, Dugan LL. Early elevation of cochlear reactive oxygen species following noise exposure. Audiol. Neurootol. 4:229-236, 1999b.

Ohlemiller KK, McFadden SL, Ding DL, Lear PM, Ho YS. Targeted mutation of the gene for cellular glutathione peroxidase (Gpx1) increases noise-induced hearing loss in mice. J. Assoc. Res. Otolaryngol. 1:243-254, 2000.

Quirk WS, Shivapuja BG, Schwimmer CL, Seidman MD. Lipid peroxidation inhibitor attenuates noise-induced temporary threshold shifts. Hear. Res. 74(1-2):217-220, 1994.

Rao D, Fechter LD. Protective effects of phenyl- $N$-tert-butylnitrone on the potentiation of noise-induced hearing loss by carbon monoxide. Toxicol. Appl. Pharmacol. 167:125-131, 2000.

Rybak LP, Ravi R, Somani SM. Mechanism of protection by diethyldithiocarbamate against cisplatin ototoxicity: antioxidant system. Fundam. Appl. Toxicol. 26:293-300, 1995.

Rybak LP, Husain K, Whitworth C, Somani SM. Dose dependent protection by lipoic acid against cisplatin-induced ototoxicity in rats: antioxidant defense system. Toxicol. Sci. 47(2):195-202, 1999. 
SeIdman MD, ShIVAPuja BG, Quirk WS. The protective effects of allopurinol and superoxide dismutase on noise-induced cochlear damage. Otolaryngol. Head Neck Surg. 109:1052-1056, 1993.

Sha SH, TAYLOR R, Forge A, Schacht J. Differential vulnerability of basal and apical hair cells is based on intrinsic susceptibility to free radicals. Hear Res 155:1-8, 2001.

Trudeau-Lame Me, Kalgutkar AS, LaFontaine M. Pharmacokinetics and metabolism of the reactive oxygen scavenger alphaphenyl- $N$-tert-butylnitrone in the male Sprague-Dawley rat. Drug Metab. Dispos. 31:147-152, 2003.

van Bladeren PJ, Delbressine LP, Hoogeterp JJ, Beaumont AH, Breimer DD, Seutter-Berlage F, van der Gen A. Formation of mercapturic acids from acrylonitrile, crotononitrile, and cinnamonitrile by direct conjugation and via an intermediate oxidation process. Drug Metab. Dispos. 9(3):246-249, 1981.
WAY JL. Cyanide intoxication and its mechanism of antagonism. Ann. Rev. Pharmacol. Toxicol. 24:451-481, 1984.

Weisiger R, Fidovich I. Superoxide dismutase. Organelle specificicity. J. Bio. Chem. 248:3528-3592, 1973.

Yamane H, Nakai Y, Takayama M, Iguchi H, Nakagawa T, Kojima A. Appearance of free radicals in the guinea pig inner ear after noise-induced acoustic trauma. Eur. Arch. Otorhinolaryngol. 252:504-508, 1995.

Yamasoba T, Schacht J, Shoji F, Miller JM. Attenuation of cochlear damage from noise trauma by an iron chelator, a free radical scavenger and glial cell line-derived neurotrophic factor in vivo. Brain Res. 815:317-325, 1999.

Young JS, Upchurch MB, Kaufman MJ, Fechter LD. Carbon monoxide exposure potentiates high-frequency auditory threshold shifts induced by noise. Hear. Res. 26:37-43, 1987. 